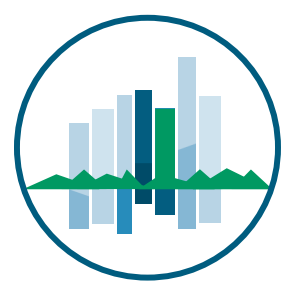

True Smart and Green City?

8th Conference of the

International Forum on Urbanism

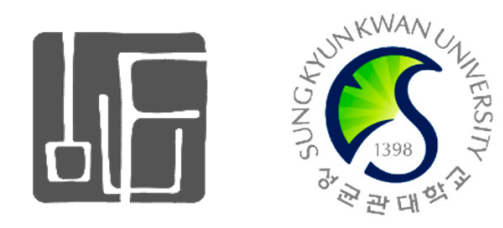

Conference Proceedings Paper

\title{
Environmental Urban Design and Planning Rules and their Impact on Street Spaces in Hong Kong and Macau
}

\author{
Hendrik Tieben ${ }^{1, *}$, Joanna Chu ${ }^{1}$, Nuno Soares ${ }^{1,2}$ and Edward Yiu ${ }^{1}$ \\ 1 The Chinese University of Hong Kong, Shatin, Hong Kong, China \\ 2 Centre for Architecture and Urbanism, Macau, China \\ * Author to whom correspondence should be addressed; Tel.: +852-6741-3262; Fax: +852-3942-0982; \\ E-mail: hktieben@cuhk.edu.hk
}

\begin{abstract}
While the knowledge about smart and green cities is quickly increasing, it remains often difficult to translate this knowledge into practice and achieve significant improvements of urban conditions on the ground. One of the main tools of governments to implement green policies are urban rules (including building regulations, urban guidelines and incentives). This paper compares the urban rules implemented, changed or repealed in Hong Kong and Macau to improve the cities' urban environment and investigates their impact on the quality of their street spaces. In the context of climate change, reduction of carbon emission and efficient use of resources, many cities are considering densification. According to the United Nations Department of Economic and Social Affairs, the Chinese Special Administrative Regions Macau and Hong Kong are two of the World's densest territories (rank 1 and 4) and thus important reference points. For this comparative study, they offer complementary insights: Hong Kong has been one of the main models for Asian high-density cities and started in 2001 with the implementation of new "greening incentives". Macau, while having even higher population density than Hong Kong, could preserve much of its historical center with its traditional streetscapes. Macau, thus, was listed 2005 as UNESCO World Heritage site. Today Macau SAR Government, however, is considering to follow the example of Hong Kong and repeal its "street shadow rule", which so far, has been an essential tool to maintain the traditional streetscapes. Hong Kong, on the other hand, after repealing its "street shadow rule" in 1987, has still to cope with the massive increase in development density which followed and experienced ambivalent results after the implementation its recent "greening incentives". The paper compares Hong Kong and Macau's implementation of different environmental rules and incentives over time and identifies their hurdles to become "truly green" cities.
\end{abstract}


Keywords: urban rules; urban design; high density; green urbanism and street spaces

\section{Introduction}

This paper compares environmental rules in Hong Kong and Macau with particular focus on their impact on street spaces. The paper is organized according to three kinds of rules in the chronological order in which they occurred: (1) Street Shadow Rules, (2) Density Control Rules and (3) Greening Incentives. The authors investigate in which context the rules were implemented, changed or repealed and which, sometimes unexpected, consequences they had on the quality of street spaces in both cities. Street spaces were chosen as focus point, because they can be seen as the most important public spaces used by every residents and visitors, and because many urban rules were defined in relationship to streets. While the paper is organized according to three kinds of rules, all of them are related to the definition of setbacks of new constructions towards their surrounding to regulate the amount of daylight and air. The rules can be further differentiated into those that were implemented to create minimum standards (1) for the residents and employees within the new developments, (2) for the residents and employees in existing buildings and their private open spaces affected by the new developments, and (3) for the general public using public spaces affected by the developments.

\section{Results and Discussion}

\subsection{Street Shadow Rules}

Hong Kong's first environmental rules related to air-ventilation were implemented after the bubonic plague epidemic in 1903. At that time, the Buildings Ordinance (S.188) set building height limits according to the width of the fronting street. This is said to be evolved into street shadow rules. The first street shadow regulations followed in 1935 with the enactment of the Buildings Ordinance (s.51). It restricted the projection of balconies and verandahs over public streets by a maximum of 75 degrees (measured from the central axis of the street). After the Second World War, with the advancement of construction technology and building materials, the Buildings Ordinance was completely revamped in 1955, facilitating the construction of more slender and taller buildings. However, the street shadow requirement was generally retained. In 1969, it was slightly revised in 1969 with a change from 75 to 76 degrees in the Building (Planning) Regulations (s.16) and remained then in place until 1987, when the street shadow regulations were entirely repealed. This gave way to a new round of increase in building mass as well as the emergence of new building types, such as the the "pencil tower". The reasons for the repeal were stated in a Legislative Council Paper from December 8, 1987:

"The existing Regulation 16 attempts to limit the height of a building by restricting the shadow cast by the building on the street (or streets) which it fronts. Street shadow area limitations were introduced in 1969 in an attempt to modify the rigid restraints imposed by the then extant regulations controlling the height of walls. The replacement regulation was soon demonstrated to be inadequate in a number of respects. Buildings were still designed with unsightly set-backs, which later facilitated the erection of illegal structures, and the formulae for computing the permitted street shadow area proved to be so vague that many disputes followed, leading to litigation in some cases. Accordingly, the Building Authority 
evolved a policy of issuing modifications to the regulation to encourage well designed and aesthetically pleasing buildings. After a decade of issuing such modifications, there is no clear evidence that any significant diminution of day-light at street level has resulted. It is also noted that heights of buildings are indirectly controlled by virtue of the plot ratio and site coverage restraints found elsewhere in these regulations; additional controls have proved to be superfluous. With these inadequacies in mind, the Building Authority has reviewed the need for this regulation and has come to the firm conclusion that principal regulation 16 should be revoked in its entirety; amending regulation 3 provides for this." 1

The decision by the Legislative Council followed several court cases in which property developers pushed for this change. It was made shortly after the Sino-British Joint Declaration (1984) about the future Handover of the British colony to the People's Republic of China (in 1997) and during a period in which Hong Kong started to establish itself as a global financial center. Thus the repeal came handy as demand for centrally located office spaces and nearby residences had strongly increased. In the following chapter we will discuss additional mechanisms which had already been implemented in Hong Kong before the repeal of the street shadow regulations and now became the only way development intensity would be controlled.

In Macau, Legislative act $\mathrm{n}^{\circ} 1600^{2}$ stated in 1963 that in order to conveniently provide building insolation, the maximum height of each façade should not exceed the double of the street width (with exception of two cases defined in Macau's Urbanization Plan).

In the same document, also the overhang of facades over public sidewalks was defined. As expressed in Article 323 from the Legislative act $n^{\circ} 1600$ of 1963, salient facade structures like porches, had to comply with a minimum height of $2,50 \mathrm{~m}$ above the sidewalk level. Updated in 1980 with Ordinance $\mathrm{n}^{\circ}$ $42 / 80 / \mathrm{M}$ that established the prevalent $76^{\circ}$ angle "street shadow rule", these rules shaped for the coming decades new constructed streetscapes in Macau.

Still today the Ordinance $\mathrm{n}^{\mathrm{o}} 42 / 80 / \mathrm{M}^{3}$ defines building heights depending on their projected shadow area on the street. This projected shadow area is defined by three factors:

a) The line representing the front of the building

b) The two perpendicular lines to the street axis, starting from the external part of the line defined in

c) The line defined by the horizontal plan projection of the upper part of the building that confronts the street, by a $76^{\circ}$ angle with the horizontal plan that crosses the middle of the building front.

As in Hong Kong before 1987, there are additional rules set in the DSSOPT 01/20094 regulation for the building height, plot ratio, as well as health conditions within buildings.. According to this regulation, building heights permitted in RAEM and lot building regulations depend on the factors: Adjacent street widths, building height classes, main building uses, and the application of land occupation and soil use indexes.

\footnotetext{
${ }^{1}$ Legislative Council Paper, December 8, 1987 (LW(T)266/32/30, Appendix 4 - XCB/LCB(87)66).

http://sc.legco.gov.hk/sc/library.legco.gov.hk/search/.b1103227/.b1103227/1,1,1,B/l962 b1103227\&FF=\&1,0,0,0

${ }^{2}$ Legislative act $\mathrm{n}^{\circ} 1600$, July 31, $1963 \mathrm{http}: / /$ bo.io.gov.mo/bo/i/63/30/dil1600.asp

${ }^{3}$ Ordinance $n^{\circ}$ 42/80/M, November 15, 1980 http://bo.io.gov.mo/bo/i/80/46/declei42.asp

${ }^{4}$ Regulation n 01/DSSOPT/2009 http://www.dssopt.gov.mo/uploads/wizdownload/201012/190 kjrih.pdf
} 
Buildings were classified according to height, in different classes. ${ }^{5} \mathrm{Class} \mathrm{P}$ and $\mathrm{M}$ buildings have until today to comply with the following three conditions, in accordance to the DSSOPT 01/2009 regulation:

a) Façade plan or plans, in case it includes advances or set backs (including vertical occupation, but excluding the overhang on the facade), cannot exceed the semi plan with origin on the street axis, forming a 76 degree angle to the horizontal. Low walls in set back buildings and building upper floors are not considered for the angle calculation.

b) In the case of a corner building, or lots confining with different width streets or different level, the most favourable situation applies to the building height calculation, complying with the maximum building depth of 15 meters.

c) The number of set backs is determined according to a), and regarding the class $\mathrm{M}$ height limit.

Figure 1. Acceptable situation (left side) Not acceptable situation (right side) (Regulation $\mathrm{n}^{\mathrm{o}}$ 01/DSSOPT/2009, 2009, p.14).
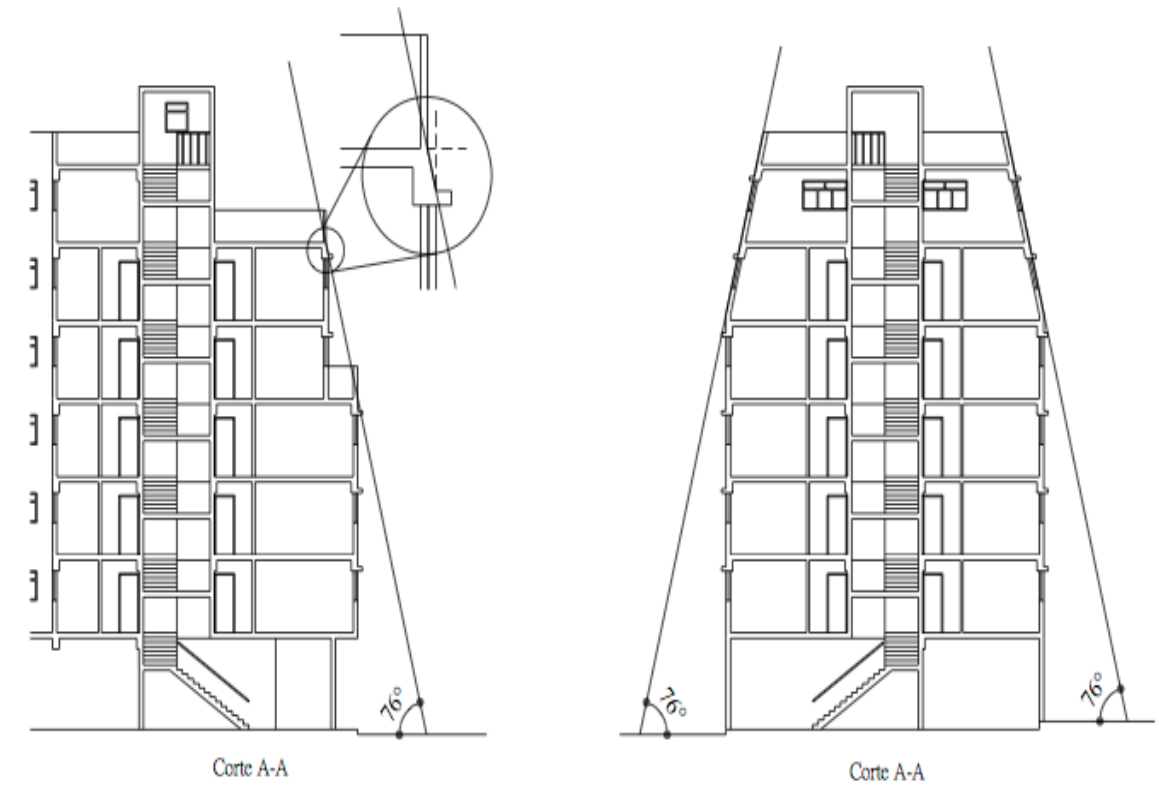

In general, constructions in all zones of Macau have to comply with the "Shadow Rule", with one exception, the sub-zone 6-2, where it doesn't applies, in accordance to Order nº 83/20086. Given Macau's significant heritage areas, the DSSOPT 01/2009 regulation, also defined areas in which only two storey set backs in a single plan are permitted. Macau's "Shadow Rule" thus is still in place, however, in the run-up to his re-election in December 2014, Macau SAR's Chief Executive Fernando Chui Sai On put its future into question and the discussion about the repeal of this rule still continues.

\footnotetext{
5 Building height classification:

Class $\mathbf{P}$ (Small): Maximum building height $9 \mathrm{~m}$

Class M (medium): Building height from 9meters to 20,5 meters

Class A (Tall): Building height from 20,5 meters to 50 meters, subdividing to two sub-classes:

Class MA (Very tall): Building height superior to 50 meters

Regulation n 01/DSSOPT/2009 http://www.dssopt.gov.mo/uploads/wizdownload/201012/190 kjrih.pdf

${ }^{6}$ Order n 83/2008, April 16, 2008 http://bo.io.gov.mo/bo/i/2008/15/despce.asp - 83
} 
Figure 2. Area where is only admissible the construction of two storey set backs (Regulation $n^{\circ}$ 01/DSSOPT/2009, 2009, p.22).

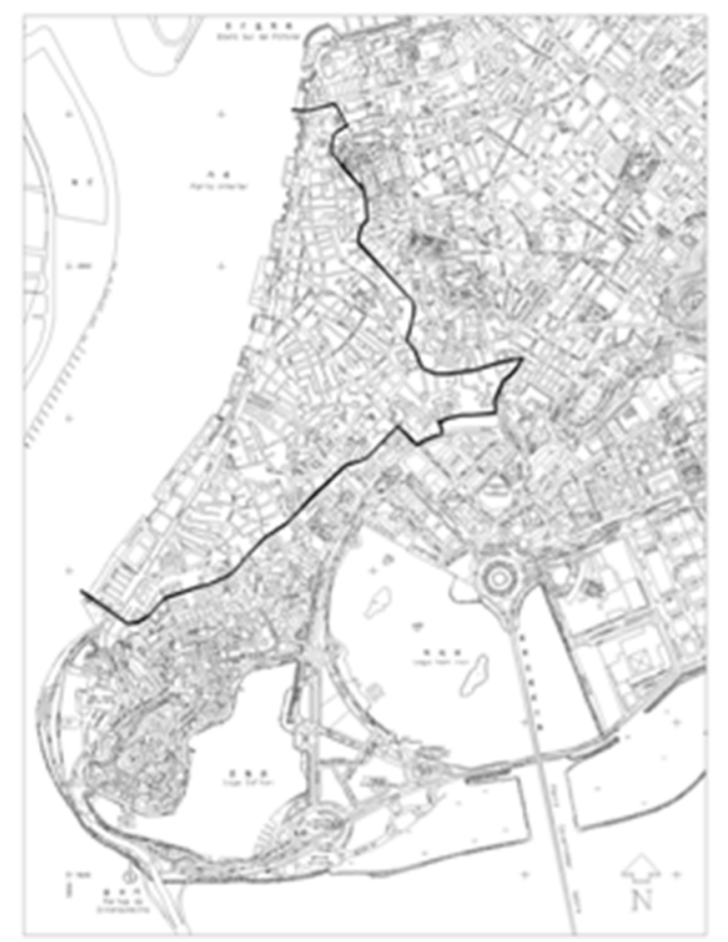

\subsection{Density Control}

In addition to the street shadow regulation, Hong Kong's colonial government used additional rules to define development intensities since 1955. When the Buildings Ordinance (HK) was revamped at that time, development intensity control was fundamentally changed from a volume control mechanism to a plot-ratio and site-coverage control mechanism. And, a new set of density control rules was developed by enacting the Building (Planning) Regulations in 1962 and implemented in 1966. From then on, the concessionary permission of projected balconies or verandahs over public streets was repealed. Thus, in the design of new buildings the upper floors had to set back to the property line allowing more light and air to reach the streets and creating narrower floor planes.

Unlike the previous volume control mechanism, the new plot-ratio and site-coverage control didn't include any height limits, but instead created a trade-off schedule: The higher a building grew, the lower its site-coverage became. Permitted plot ratio became subject to the land use and site classifications.

In contrast to rules in other high-rise cities - especially New York - Hong Kong's Building (Planning) Regulations (s.20(3)) permitted a 100\% site coverage for the lower part of buildings. First only a one storey high podium was allowed but then the podium height could be increased up to $15 \mathrm{~m}$, resulting in Hong Kong's typical podium towers. Through this rule, Hong Kong kept its vibrant narrow streets aligned with active retail frontages, while in New York, with the implementation of its FAR bonus system, streets were extended with large new plazas, as part of new tower projects. Given the high incomes achievable from retail space, Hong Kong's developers were keen to keep a maximum of commercial space near the pedestrian flow. Additionally, the low podiums could be used to provide parking spaces for an increasing number of private cars. While the users within the private residential 
and office towers benefited from the better provision of daylight, air and views generated by the plot ratio system, the users of the public streets suffered from the reduction of air ventilation brought by an $100 \%$ site coverage, and the additional increase of air pollution brought by the growing vehicular traffic.

Also Macau had introduced a plot ratio system according to which densities for particular site classes were allowed. Like in Hong Kong, the site classes were defined by the number adjacent streets of a building lot. Thus in both cities the largest developments continue to occur on the corner sites of street block, following the logic that the impact on surrounding private properties here is lower. This contrasts, however, for instance to cities such as Portland, which by purpose reduced building heights on corner sites to bring more daylight and air into the streets.

Problems occurred in Macau at the height of the casino boom in the 2000s. Ordinance $\mathrm{n}^{\circ} 42 / 80 / \mathrm{M}$, which defined the projected shadow rule, also states that, regarding buildings confining with the sea, parks or squares, the building height shall be defined in a case by case standard, according to partial studies from DSSOPT and Planning Coordination Services Bureau. This created loopholes, which led to several controversial projects near the waterfronts. According to document published in 2007 by the Macau Urbanism and Planning Department ${ }^{7}$, the zone around Av. Almeida Ribeiro had a maximum permitted height limit of $20,5 \mathrm{~m}$. The zone encompasses all the area around the Almeida Ribeiro street, as well as Macau's Inner Harbour. Any new building here had to comply with a maximum height limit of $20,5 \mathrm{~m}$, classified as $\mathrm{M}$ class (medium class) building.

Figure 3. RAEM General Plan - Almeida Ribeiro area (DPU, 2007).

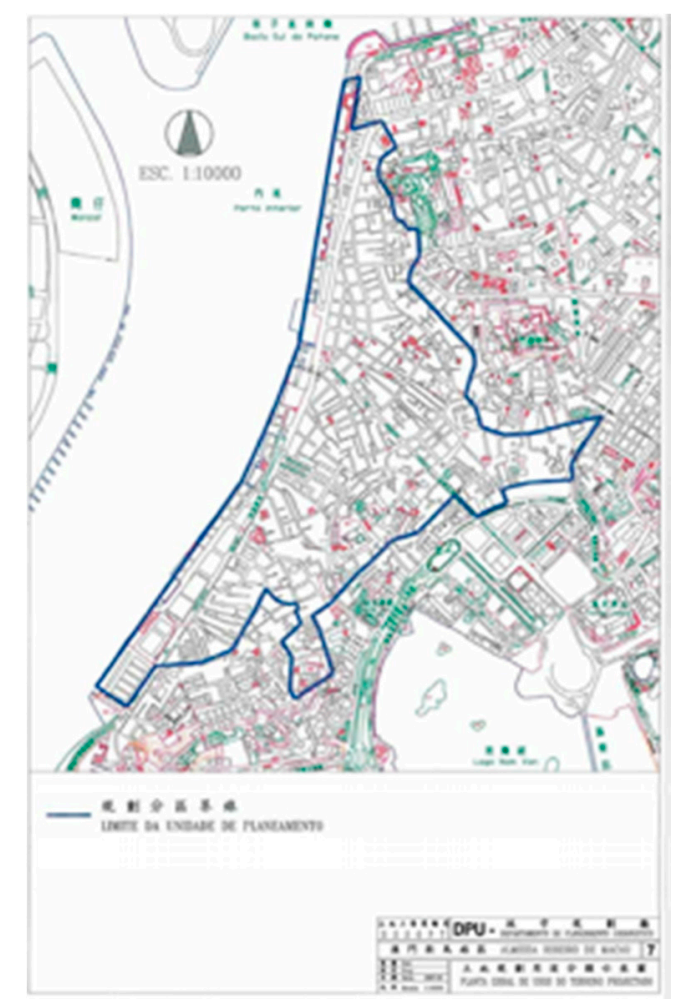

Nevertheless, in 2008, the casino resort Ponte 16 opened at the western end of Avenida Almeida Ribeiro, with a building height of over 50m (as a MA (very tall) building). At the same time in the same zone further south, the Riviera development was completed, a 45-storey double-tower complex with

\footnotetext{
${ }^{7}$ RAEM General Plan, DPU, March, 2007 http://urbanplanning.dssopt.gov.mo/download/PLANTA_GERAL.pdf
} 
over 500 residential units. With a building height of approximately $145 \mathrm{~m}$, it also would be classified in Macau as a class MA building and shouldn't have been permitted in this area.

Figure 4. River view of the Inner Harbour. On the left side Ponte 16, on the right side, Riviera building. (Photo by Nuno Soares / CURB, 2015).

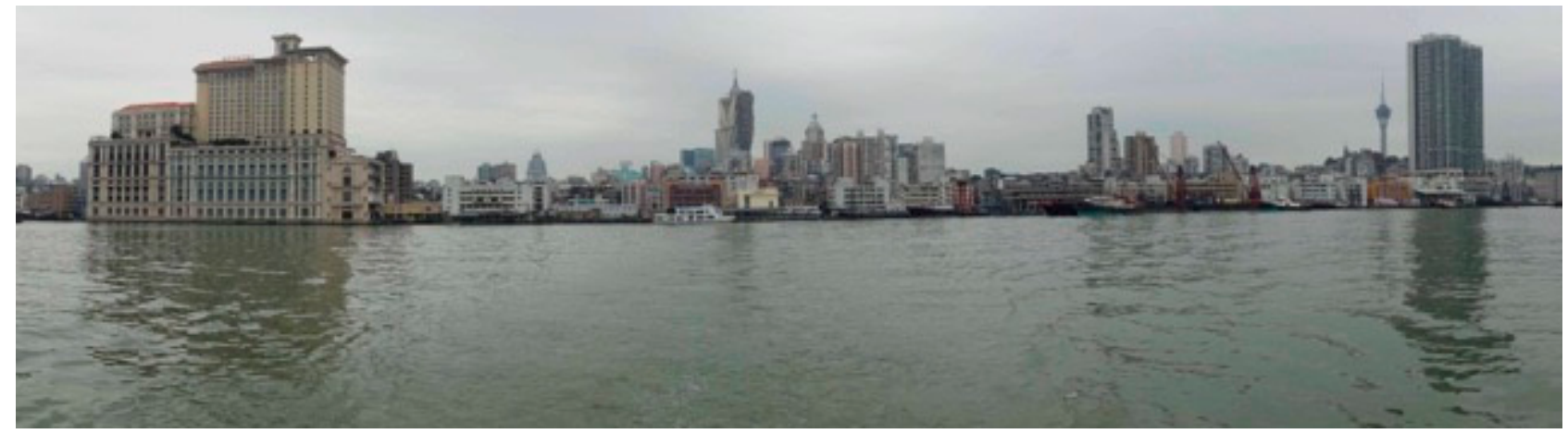

While similar large developments currently are less likely, the exceptions from the shadow rule for sites adjacent to waterfronts and public spaces - decided on a case-by-case manner - remains a problematic loophole. It also indicates, what might easily happen to the UNESCO World Heritage city, due to the high development pressure, if the shadow law generally would be repealed without having any other workable system in place.

\subsection{Greening Incentives}

The negative effects of Hong Kong's density control mechanisms created in the 1950-60s were addressed in the following years by different gross floor area (GFA) incentives for set-back and street widening. S.22 of the Building (Planning) Regulations specify that a dedication of set-back area for public passages or a surrender of land for road widening at ground level can attract a bonus GFA that equals to 5 times the area surrendered/dedicated or less than $20 \%$ of the permissible plot ratio, whichever is the less. Besides the statutory specified bonus GFA for surrender and dedication, the Building Authority also grants bonus GFA if a footbridge is provided to connect two buildings for pedestrian as to reduce pedestrian congestion on the ground level of the Central Business Districts.

Since the 2000s, the Hong Kong SAR Government has launched a series of Joint Practice Notes (JPN 1 to 4 ) to incentivise the design of green features in new buildings by granting concessionary GFA. APP151 and APP-152 in particular specify the requirements of set-back or street widening and the concessionary GFA in return. ${ }^{8}$ In the following years, however, problems of these incentivised "green features" became apparent, especially as large "wall buildings" appeared near the water fronts, which had been made possible by the large amount of the additionally granted concessionary GFA. After growing public concerns, the system was revised in 2011 by setting a cap of maximum $10 \%$ concessionary GFA (see Practice Note APP-151). Besides the cap, concessionary GFA is also required to fulfil the Sustainable Building Design (SBD) Guidelines set out in APP-152. Three key building design elements were specified in the new SBD Guidelines, which are: (1) building separation, (2) building set back and (3) site coverage of greenery. "The objectives are to achieve better air ventilation,

\footnotetext{
${ }^{8}$ http://www.bd.gov.hk/english/documents/pnap/signed/APP151se.pdf
} 
enhance the environmental quality of living space, particularly at pedestrian level, provide more greenery and mitigate the heat island effect" (APP-152).

More recently, three more parameters on density control were regulated by the Town Planning Ordinance, they are: (1) Building Height (BH), (2) Building Gap (BG) and (3) No Building Area (NBA). The rationale behind these three new parametric controls is to ensure the requirements of Air Ventilation Assessment (AVA) are achieved. However, since the implementation of the new restrictions in the Outline Zoning Plans (OZPs), there have been many judicial reviews that property developers won on the basis of procedural justice and the attempted improvements of air ventilation by the Outline Zoning Plans were quashed (HCAL38/2011, HCAL57/2011, CACV127/2012, CACV129/2012, HCAL58/2011, HCAL62/2011). Macau didn't follow Hong Kong's implementation of green incentives yet, but with its sensitive heritage sites it should learn from the experiences made in Hong Kong.

\section{Conclusions}

Street shadow rules in Hong Kong and Macau were implemented to secure minimum provision of daylight and air ventilation. As the name indicates, they were defined in relationship to streets and thus the main public spaces of these cities. The rules for development intensity control shifted the focus to controlling the impact of new developments on private properties. The control of daylight and air in public streets became less important, when new rules appeared, such as the system of site classes, which permitted in both cities much higher plot ratio for corner sites. In Hong Kong, the permission of 100\% site coverage further reduced the air quality. Macau, didn't follow this decision and thus didn't experience a similar proliferation of podium towers. It also didn't follow Hong Kong yet, to repeal its shadow law entirely. In Hong Kong, the problems of lacking more stringent regulations securing the the air quality in the public spaces of its urban areas became more apparent. In the years following the SARS epidemic (2003) detailed AVA studies were conducted in specific districts, and as a result, in 2011 its Outline Zoning Planes (OZPs) were substantial revised. However, due to legal battles of its influential property developers, the revisions of the (OZPs) had no real impact yet in practice. Macau and other cities which are considering to follow Hong Kong to revamp their planning system and encourage higher densities, should be aware on the deficiencies of Hong Kong's system including its recent "greening incentives" to achieve a more healthy environment.

\section{Acknowledgements}

This paper is part of the General Research Grant Project (453312) "Investigating the Urban Design Guidelines of the PRD cities Guangzhou, Hong Kong, Macau and Shenzhen" (Hendrik Tieben (PI) and Doreen Liu (Co-I) awarded by Research Grant Council HK.

\section{Conflict of Interest}

The authors declare no conflict of interest. 


\section{References and Notes}

1. Ng, E. Policies and Technical Guidelines for Urban Planning of High Density Cities - Air Ventilation Assessment (AVA) of Hong Kong. Building and Environment 2009, 44, 1478-1488.

2. Ng. E. Regulate for Light, Air and Healthy Living - Part III The Becoming of PNAP 278. HKIA Journal 2005, 44, 16-25.

3. Ng. E. Regulate for Light, Air and Healthy Living - Part II Regulating the Provision of Natural Light and Ventilation of Buildings in Hong Kong. HKIA Journal 2004, 37, 4-27.

4. Shelton, B.; Karakiewicz, J., Kvan, T. The Making of Hong Kong: From Vertical to Volumetric (Planning, History and Environment), 1st ed.; Routledge: Oxfordshire, England, 2011.

5. Soares, N. The Inner Harbour Background Document on the Revitalization of Macau's Vernacular Heritage. Centre for Architecture and Urbanism, Macau, 2014.

6. Wong, M.S., Nichol, J.E., Ng, E. A study of the "wall effect" caused by proliferation of high-rise buildings in Hong Kong, using GIS techniques. Landscape and Urban Planning 2011, 102, 245 253.

(C) 2015 by the authors; licensee MDPI and IFoU, This article is an open access article distributed under the terms and conditions of the Creative Commons Attribution license. 